Article

\title{
Recovery of a Bacteriocin-Like Inhibitory Substance from Lactobacillus bulgaricus FTDC 1211 Using Polyethylene-Glycol Impregnated Amberlite XAD-4 Resins System
}

\author{
Nur Fazrin Husna Abdul Aziz ${ }^{1}$, Sahar Abbasiliasi ${ }^{2}$, Zhang Jin Ng ${ }^{1}$, Mazni Abu Zarin ${ }^{1,3}$, \\ Siti Nurbaya Oslan ${ }^{4}$, Joo Shun Tan ${ }^{1,5, *}$ and Arbakariya Bin Ariff ${ }^{5,6, *}$ \\ 1 School of Industrial Technology, Universiti Sains Malaysia, Gelugor, Pulau Pinang 11800, Malaysia; \\ fazaziz93@gmail.com (N.F.H.A.A.); jinng@student.usm.my (Z.J.N.); mazniabuzarin@gmail.com (M.A.Z.) \\ 2 Halal Products Research Institute, Universiti Putra Malaysia, Serdang 43400, Selangor, Malaysia; \\ sahar@upm.edu.my \\ 3 Institute of Bioscience, Universiti Putra Malaysia, Serdang 43400, Selangor, Malaysia \\ 4 Department of Biochemistry, Faculty of Biotechnology and Biomolecular Sciences, Universiti Putra Malaysia, \\ Serdang 43400, Selangor, Malaysia; snurbayaoslan@upm.edu.my \\ 5 Bioprocessing and Biomanufacturing Research Centre, Faculty of Biotechnology and Biomolecular Sciences, \\ Universiti Putra Malaysia UPM, Serdang 43400, Selangor, Malaysia \\ 6 Department of Bioprocess Technology, Faculty of Biotechnology and Biomolecular Sciences, \\ Universiti Putra Malaysia UPM, Serdang 43400, Selangor, Malaysia \\ * Correspondence: jooshun@usm.my (J.S.T.); arbarif@upm.edu.my (A.B.A.); \\ Tel.: +60-4-6536376 (J.S.T.); +60-3-89467591 (A.B.A.)
}

Academic Editors: Manuela Pintado, Ezequiel Coscueta and Maria Emilia Brassesco Received: 18 September 2020; Accepted: 30 October 2020; Published: 16 November 2020

check for updates

\begin{abstract}
Lactobacillus bulgaricus is a LAB strain which is capable of producing bacteriocin substances to inhibit Staphylococcus aureus. The aim of this study was to purify a bacteriocin-like inhibitory substance (BLIS) produced by L. bulgaricus FTDC 1211 using an aqueous impregnated resins system consisting of polyethylene-glycol (PEG) impregnated on Amberlite XAD4. Important parameters influencing on purification of BLIS, such as the molecular weight and concentration of PEG, the concentration and $\mathrm{pH}$ of sodium citrate and the concentration of sodium chloride, were optimized using a response surface methodology. Under optimum conditions of 11\% (w/w) of PEG 4000 impregnated Amberlite XAD4 resins and $2 \%(w / w)$ of sodium citrate at $\mathrm{pH} 6$, the maximum purification factor (3.26) and recovery yield $(82.69 \% \pm 0.06)$ were obtained. These results demonstrate that AIRS could be used as an alternate purification system in the primary recovery step.
\end{abstract}

Keywords: purification; bacteriocin-like inhibitory substance; lactic acid bacteria; polymer; resin

\section{Introduction}

Staphylococcus aureus skin infections pose a major concern to public health, largely owing to the steadily increasing prevalence of drug resistant isolates [1]. As an alternative mode of treatment, bacteriocins have been shown to possess antimicrobial efficacy against multiple drug resistant strains. This reveals the huge potential of bacteriocin as an alternate drug in the pharmaceutical industry. Bacteriocins are ribosomally synthesized, antimicrobial peptides or proteins produced by various microorganisms which have the ability to inhibit the growth of bacteria with closely related species. The most studied bacteriocin-producing microorganisms are lactic acid bacteria (LAB), which have the status of generally recognized as safe (GRAS) microorganisms [2]. Lactobacillus bulgaricus is a LAB 
strain which is capable of producing bacteriocin-like inhibitory substances (BLIS) to inhibit S. aureus [3]. Hence, adequate purification of BLIS from L. bulgaricus is necessary for its characterization and potential industrial application.

Different methods have been applied for the recovery of BLIS from fermentation broths. The most frequently used methods for its isolation, concentration, and purification include salt precipitation, various combinations of gel filtration, different chromatography techniques and aqueous two phases [4-6]. Most of these methods produce satisfactory results only on a small scale, i.e., with low yields. Furthermore, they are expensive, difficult to handle and not applicable on a large scale [7]. The increasing demand for natural products with bioactive properties calls for new approaches in the biomanufacturing of such products. However, the limiting factor towards their large-scale production has always been the absence of a suitable process to overcome the limited product recovery. In this respect, recent advances in biotechnology have been looked upon as alternative approaches to surmounting this constraint.

Aqueous impregnated resin system (AIRS) is a purification technique for the separation, extraction and concentration of biomolecules. So far, AIRS has only been tested on the purification of enzymes such as esterase and lipase [8,9]. This study evaluated the feasibility of AIRS for the recovery of BLIS from the culture of L. bulgaricus FTDC 1211. As far we know, this is the first study on the purification of a peptide like BLIS using Amberlite XAD4 in AIRS. The effects of influencing factors such as the molecular weight and concentration of PEG, concentration and $\mathrm{pH}$ of extraction solution (sodium citrate) and concentration of sodium chloride $(\mathrm{NaCl})$ on the recovery of BLIS were also assessed in this study.

\section{Results}

\subsection{Antimicrobial of BLIS from L. bulgaricus FTDC 1211}

Figure 1 shows that the average diameter of the inhibition zone formed in the presence of CCFS from L. bulgaricus FTDC 1211 was $18.34 \mathrm{~mm}$, contributing $2056.4 \mathrm{~mm}^{2} / \mathrm{mL}$ of inhibition of $S$. aureus. The BLIS activity was comparable to that of the control $(15 \mathrm{mg} / \mathrm{mL}$ of streptomycin) $(2102.5 \mathrm{~mm} / \mathrm{mL})$. Hence, the CCFS from L. bulgaricus FTDC 1211 was used for subsequent experiments.

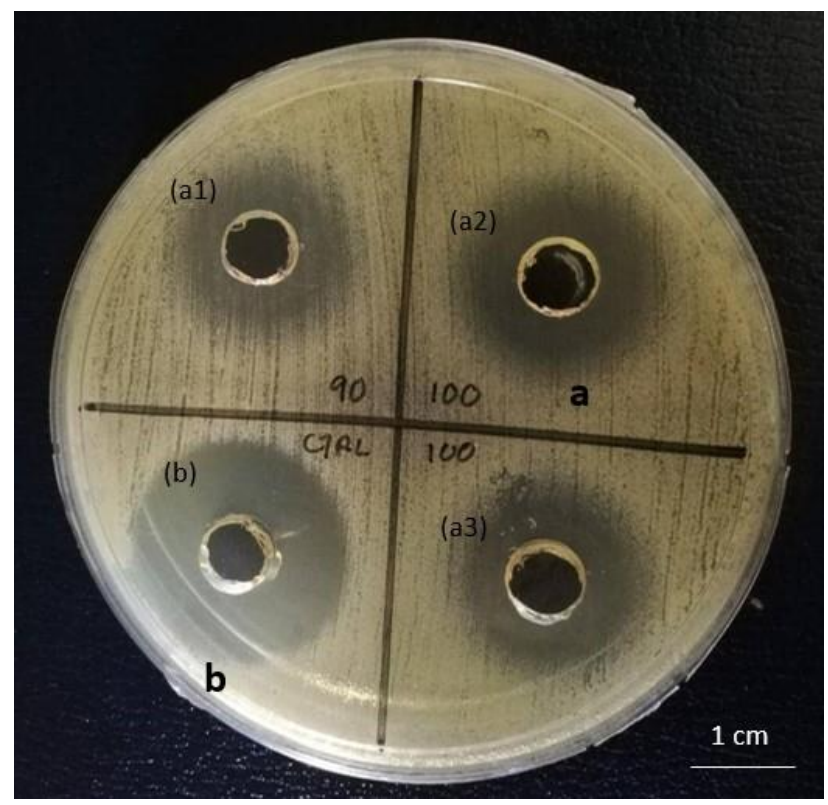

Figure 1. Antimicrobial activity of (a1) 90\% (v/v) of CCFS from L. bulgaricus FTDC1211, (a2,a3) 100\% $(v / v)$ of CCFS from L. bulgaricus FTDC1211 in duplicate and (b) control with $15 \mathrm{mg} / \mathrm{mL}$ of streptomycin against $S$. aureus. 


\subsection{Purification of BLIS from L. bulgaricus FTDC 1211 Using AIRS}

\subsubsection{Effect of Molecular Weight and Concentration of PEG}

BLIS produced by L. bulgaricus FTDC 1211 was purified via a single-step AIRS. The effect of the molecular weight and concentration of PEG on purification of BLIS by AIRS is shown in Table 1. The results showed that $10 \%$ of PEG 4000 impregnated Amberlite XAD4 resins had a higher purification factor (1.64) and recovery yield (82.63\%) than other molecular weights and concentrations of PEG. It was observed that an increased concentration of PEG decreased the purification factor. The recovery of BLIS in PEG 4000 and PEG 8000 reduced markedly when the concentration of PEG increased from $10 \%$ to $40 \%$. Hence, $10 \%(w / w)$ of PEG 4000 with the highest purification factor was used in further experiments.

Table 1. The purification factor and recovery yield of different molecular weights and concentrations of PEG.

\begin{tabular}{cccc}
\hline PEG Molecular Weight $\mathbf{g} / \mathbf{m o l}$ & Concentration $\mathbf{\%}(\boldsymbol{w} / \boldsymbol{w})$ & Purification Factor & Recovery Yield $\%$ \\
\hline \multirow{2}{*}{2000} & 10 & 0 & 0 \\
& 20 & 1.15 & 81.79 \\
& 30 & 1.15 & 84.89 \\
4000 & 40 & 1.20 & 84.25 \\
& 10 & 1.64 & 82.63 \\
& 20 & 1.40 & 86.68 \\
\multirow{2}{*}{6000} & 30 & 1.10 & 65.50 \\
& 40 & 0.77 & 47.83 \\
& 10 & 1.16 & 55.54 \\
& 20 & 1.10 & 78.16 \\
& 30 & 1.06 & 84.46 \\
& 40 & 1.00 & 86.13 \\
& 10 & 1.30 & 80.41 \\
& 20 & 0.82 & 69.10 \\
& 30 & 0.71 & 72.38 \\
& 40 & 0.62 & 62.38 \\
\hline
\end{tabular}

\subsubsection{Effect of Sodium Citrate Concentration}

Figure 2A shows the effect of the sodium citrate concentration $(2.5,5,7.5$ and $10 \%(w / w))$ in the extraction solution on the purification factor and yield of BLIS in AIRS. The highest purification factor (2.4) was obtained with $2.5 \%$ sodium citrate. However, the recovery of BLIS was reduced to $67.4 \%$. The purification factor showed a decreasing trend as the concentration of sodium citrate increased. Hence, $2.5 \%(w / w)$ of sodium citrate was used in subsequent experiments.

\subsubsection{Effect of $\mathrm{pH}$ of Sodium Citrate}

Figure $2 \mathrm{~B}$ shows the effect of the $\mathrm{pH}$ of sodium citrate on the purification factor and recovery yield by manipulating the charges of the protein in the system. Among five different $\mathrm{pHs}$ of sodium citrate $(5,6,7,8$ and 9), a pH of 6 showed the highest purification factor (2.6) and recovery yield (76.7\%). As the $\mathrm{pH}$ increased from 6 to 9 , the purification factor gradually reduced.

\subsubsection{Effect of Different Concentration of $\mathrm{NaCl}$}

The effect of $\mathrm{NaCl}$ concentration on purification factor and recovery yield of BLIS is presented in Figure $2 \mathrm{C}$. The addition of $4 \%(w / w) \mathrm{NaCl}$ into the extraction solution showed the highest purification factor (2.65) and recovery yield (80.67\%). When the $\mathrm{NaCl}$ concentration increased to $4 \%(w / w)$, the purification factor gradually increased. Further increasing the $\mathrm{NaCl}$ concentration resulted in a decrease in purification factor. 
(A)

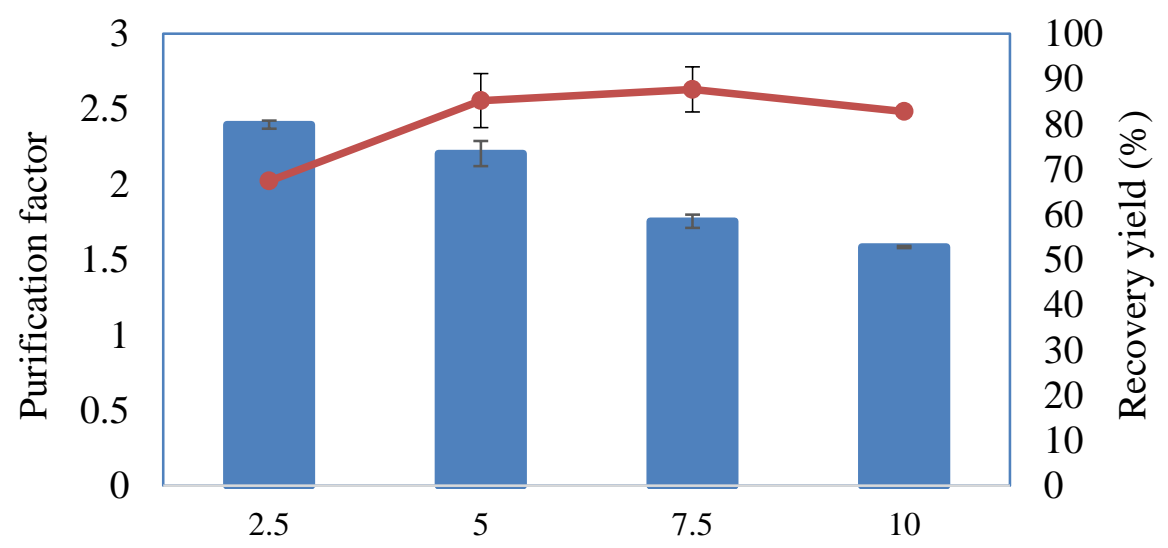

Sodium citrate concentration $(\%)$

(B)

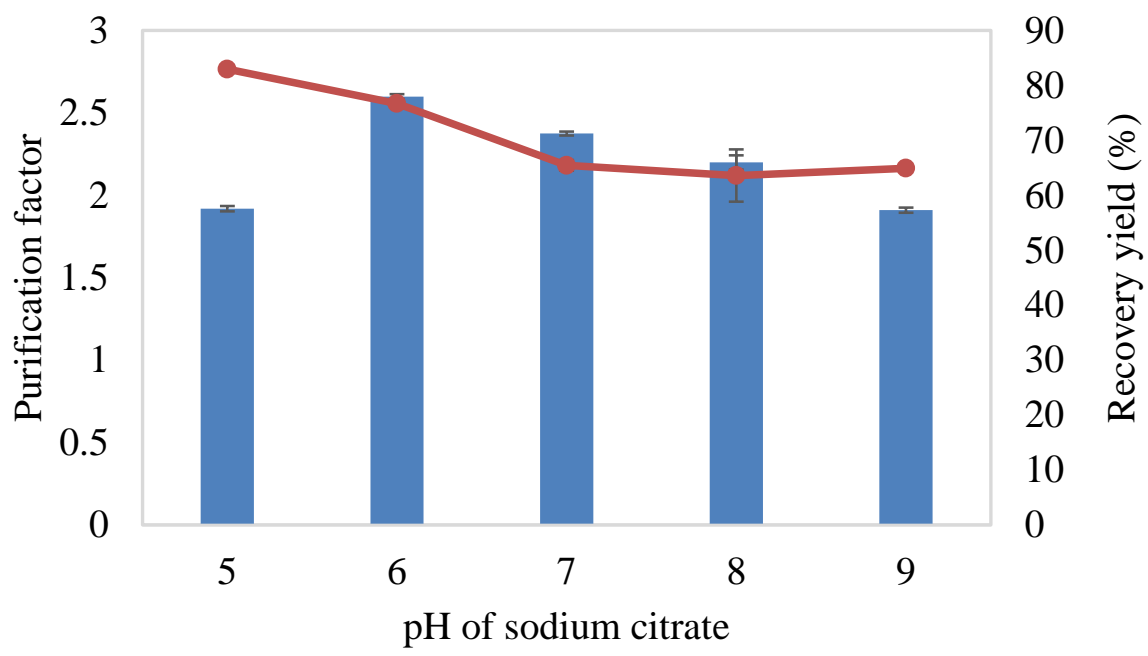

(C)

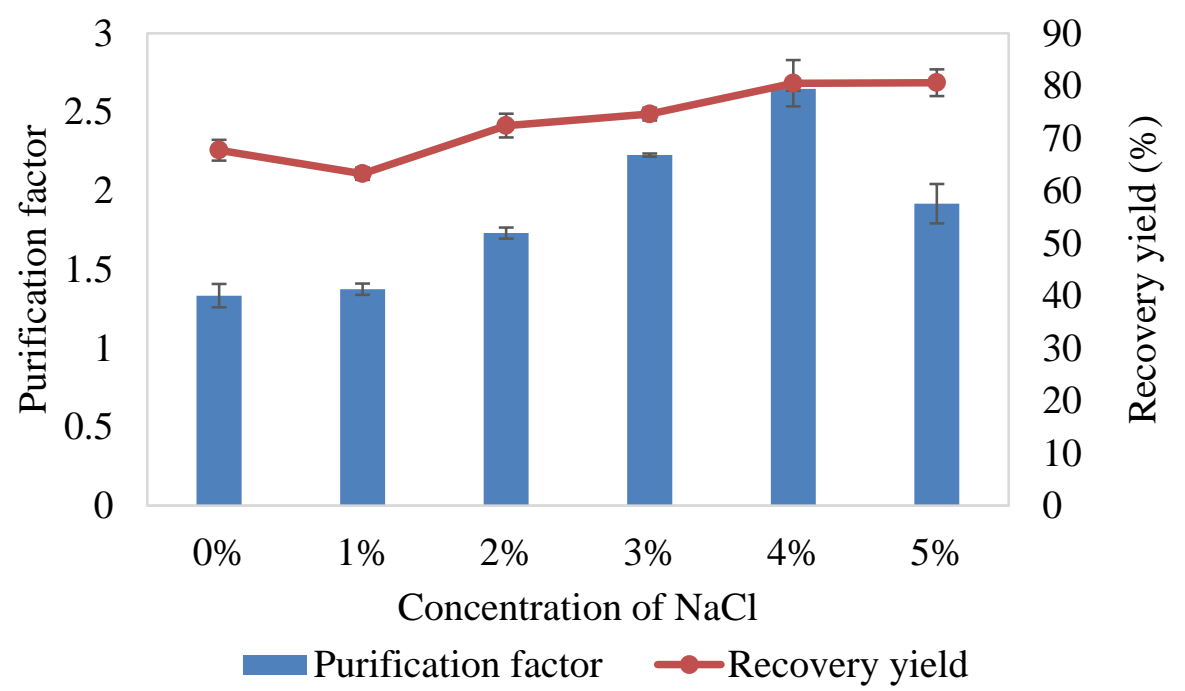

Figure 2. The purification factor and recovery yield achieved for different concentration of sodium citrate (A), $\mathrm{pH}$ of sodium citrate $(\mathbf{B})$ and $\mathrm{NaCl}(\mathbf{C})$. The results reported were expressed as a mean of triplicate reading with an estimated error of $\pm 5 \%$.

\subsection{Optimization of Purification Parameters Using Response Surface Methodology}

A five level, full factorial central composite design (CCD) with three independent variables (concentration of PEG, $\mathrm{pH}$ of sodium citrate and concentration of sodium citrate) was applied to 
maximize the recovery of BLIS in AIRS. The actual and predicted purification factor and recovery yield $(\%)$ are presented in Table 2 . In this study, the maximum purification factor $(2.98 \pm 0.03)$ and recovery yield $(84.28 \% \pm 0.06)$ were predicted to be obtained under optimum conditions, i.e., $11.44 \%(w / w)$ PEG 4000 and $1.98 \%(w / w)$ sodium citrate at a $\mathrm{pH}$ of 6.06 .

Table 2. The actual and predicted purification factor and recovery yield of BLIS in AIRS with different PEG concentration, $\mathrm{pH}$ and concentration of sodium citrate.

\begin{tabular}{|c|c|c|c|c|c|c|}
\hline \multirow{2}{*}{ PEG Concentration } & \multirow{2}{*}{ pH of Sodium Citrate } & \multirow{2}{*}{$\begin{array}{l}\text { Concentration of } \\
\text { Sodium Citrate }\end{array}$} & \multicolumn{2}{|c|}{ Purification Factor } & \multicolumn{2}{|c|}{ Recovery Yield (\%) } \\
\hline & & & Actual & Predicted & Actual & Predicted \\
\hline 10.00 & 5.00 & 1.00 & 2.46 & 2.33 & 86.32 & 91.87 \\
\hline 15.00 & 5.00 & 1.00 & 1.79 & 1.80 & 88.02 & 82.62 \\
\hline 10.00 & 7.00 & 1.00 & 2.44 & 2.48 & 86.58 & 95.34 \\
\hline 10.00 & 5.00 & 5.00 & 0.31 & 0.23 & 88.44 & 35.94 \\
\hline 15.00 & 5.00 & 5.00 & 1.17 & 1.05 & 78.54 & 94.72 \\
\hline 10.00 & 7.00 & 5.00 & 2.53 & 2.44 & 83.36 & 49.01 \\
\hline 15.00 & 7.00 & 5.00 & 1.22 & 1.27 & 83.87 & 42.70 \\
\hline 8.30 & 6.00 & 3.00 & 1.33 & 1.46 & 91.24 & 49.16 \\
\hline 12.50 & 4.32 & 3.00 & 1.52 & 1.69 & 92.34 & 95.26 \\
\hline 12.50 & 7.68 & 3.00 & 2.03 & 2.00 & 83.87 & 73.35 \\
\hline 12.50 & 6.00 & -0.36 & 2.29 & 2.31 & 84.38 & 91.07 \\
\hline 12.50 & 6.00 & 6.36 & 1.54 & 1.65 & 80.57 & 89.08 \\
\hline 12.50 & 6.00 & 3.00 & 3.00 & 2.84 & 82.35 & 82.21 \\
\hline 12.50 & 6.00 & 3.00 & 2.87 & 2.84 & 82.60 & 82.21 \\
\hline 12.50 & 6.00 & 3.00 & 2.83 & 2.84 & 85.65 & 82.21 \\
\hline 12.50 & 6.00 & 3.00 & 2.50 & 2.84 & 83.87 & 82.21 \\
\hline 12.50 & 6.00 & 3.00 & 2.88 & 2.84 & 83.7 & 82.21 \\
\hline 12.50 & 6.00 & 3.00 & 2.94 & 2.84 & 81.58 & 82.21 \\
\hline \multicolumn{7}{|c|}{ Predicted optimum conditions } \\
\hline 11.44 & 6.06 & 1.98 & $3.25 \pm 0.03$ & 2.98 & $82.69 \pm 0.06$ & 84.28 \\
\hline
\end{tabular}

An analysis of variance (ANOVA) for the purification factor and recovery yield was performed based on the experimental data presented in Table 3. Fisher's F-test for purification factor showed that the model was capable of representing the relationships between the purification factor (response) with the three selected factors (concentration of PEG, pH of sodium citrate and concentration of sodium citrate). The $F$-value for the purification factor of model (32.90) with a $p$-value of $<0.0001$ indicated that the model is significant at 95\% confidence level. Meanwhile, the $p$-value for lack of fit for purification factor model (0.3904) implied that the model is not significantly relative to pure error. The $p$-value for the interaction between PEG concentration and salt ( $p$-value $=0.0002)$, PEG concentration and salt concentration $(p$-value $=0.0028)$ and $\mathrm{pH}$ of salt and salt concentration $(p$-value $=0.0002)$ indicated that the interaction between the respective parameters affected the purification factor of BLIS. On the other hand, the $F$-value for the recovery yield was 2.56 with $p$-value $>0.1001$, indicating that the model is not significant at a $95 \%$ confidence level. Hence, there is no fitted model for the recovery yield. This could be due to insignificant variations in the recovery yield for low or high levels of factors. 
Table 3. Analysis of variance (ANOVA) for response surface quadratic model of purification factor (a) and recovery yield $(\mathrm{b})$ of BLIS.

\begin{tabular}{|c|c|c|c|c|c|}
\hline Source & Sum of Squares & Degree of Freedom & Mean Square & $F$ Value & $\begin{array}{l}p \text {-Value } \\
\text { Prob }>F\end{array}$ \\
\hline \multicolumn{6}{|c|}{ (a) Purification Factor } \\
\hline Model & 9.82 & 9 & 1.09 & 32.90 & $<0.0001^{a}$ \\
\hline A & 0.97 & 1 & 0.97 & 29.18 & 0.0006 \\
\hline B & 0.089 & 1 & 0.089 & 2.69 & 0.1393 \\
\hline $\mathrm{C}$ & 0.40 & 1 & 0.40 & 11.97 & 0.0086 \\
\hline $\mathrm{AB}$ & 1.30 & 1 & 1.30 & 39.31 & 0.0002 \\
\hline $\mathrm{AC}$ & 0.60 & 1 & 0.60 & 18.12 & 0.0028 \\
\hline $\mathrm{BC}$ & 1.39 & 1 & 1.39 & 41.85 & 0.0002 \\
\hline$A^{2}$ & 3.49 & 1 & 3.49 & 105.21 & $<0.0001$ \\
\hline$B^{2}$ & 1.70 & 1 & 1.70 & 51.15 & $<0.0001$ \\
\hline$C^{2}$ & 1.25 & 1 & 1.25 & 37.78 & 0.0003 \\
\hline Residual & 0.27 & 8 & 0.033 & & \\
\hline Lack of fit & 0.11 & 3 & 0.038 & 1.23 & $0.3904^{b}$ \\
\hline Pure error & 0.15 & 5 & 0.031 & & \\
\hline Cor Total & 10.08 & 17 & & & \\
\hline \multicolumn{6}{|c|}{ (b) Recovery Yield } \\
\hline Model & 157.69 & 9 & 17.52 & 2.56 & $0.1001^{b}$ \\
\hline A & 5.07 & 1 & 5.07 & 0.74 & 0.4145 \\
\hline B & 9.44 & 1 & 9.44 & 1.38 & 0.2740 \\
\hline $\mathrm{C}$ & 26.68 & 1 & 26.68 & 3.90 & 0.0838 \\
\hline $\mathrm{AB}$ & 9.65 & 1 & 9.65 & 1.41 & 0.2691 \\
\hline $\mathrm{AC}$ & 14.34 & 1 & 14.34 & 2.09 & 0.1859 \\
\hline $\mathrm{BC}$ & 0.044 & 1 & 0.044 & $6.485 \times 10^{-3}$ & 0.9378 \\
\hline $\mathrm{A}^{2}$ & 19.07 & 1 & 19.07 & 2.79 & 0.1336 \\
\hline $\mathrm{B}^{2}$ & 28.60 & 1 & 28.60 & 4.18 & 0.0752 \\
\hline$C^{2}$ & 4.04 & 1 & 4.04 & 0.59 & 0.4645 \\
\hline Residual & 54.75 & 8 & 6.84 & & \\
\hline Lack of fit & 44.40 & 3 & 14.80 & 7.14 & $0.0295^{\mathrm{a}}$ \\
\hline Pure error & 10.36 & 5 & 2.07 & & \\
\hline Cor Total & 212.45 & 17 & & & \\
\hline
\end{tabular}

$\mathrm{A}=\mathrm{PEG}$ concentration $(\% w / w), \mathrm{B}=\mathrm{pH}$ of sodium citrate, $\mathrm{C}=$ concentration of sodium citrate $(\% w / w)$, ${ }^{\text {a Significant }}$ and ${ }^{\mathrm{b}}$ Not significant.

From the statistical analysis, it was found that the most suitable fitted model for the purification factor was quadratic polynomial. The predicted response for the purification factor is in Equation (1):

$$
\mathrm{Y}_{1}=2.84-0.43 \mathrm{~A}+0.093 \mathrm{~B}-0.20 \mathrm{C}-0.50 \mathrm{AB}+0.34 \mathrm{AC}+0.52 \mathrm{BC}-0.74 \mathrm{~A}^{2}-0.35 \mathrm{~B}^{2}-0.30 \mathrm{C}^{2}
$$

$\mathrm{A}=\mathrm{PEG}$ concentration $(\% w / w), \mathrm{B}=\mathrm{pH}$ of sodium citrate, $\mathrm{C}=$ concentration of sodium citrate $(\% w / w)$.

Figure 3 shows the 3D surface plots for the interaction between PEG concentration and $\mathrm{pH}(\mathrm{A})$, PEG concentration and salt concentration (B) and salt concentration and $\mathrm{pH}(\mathrm{C})$. A quadratic polynomial curve with an optimum point was obtained from the interaction between the parameters. Validation of the experimental data showed that the purification factor of BLIS $(3.25 \pm 0.03)$ had small variation relative to the predicted purification factor (2.98) under optimum purification conditions, i.e., $11.4 \%$ $(w / w)$ of PEG 4000 impregnated on Amberlite XAD-4 resins, 2\% $(w / w)$ of sodium citrate at $\mathrm{pH} 6$ and $4 \%$ $(w / w)$ of $\mathrm{NaCl}$. 
(A)

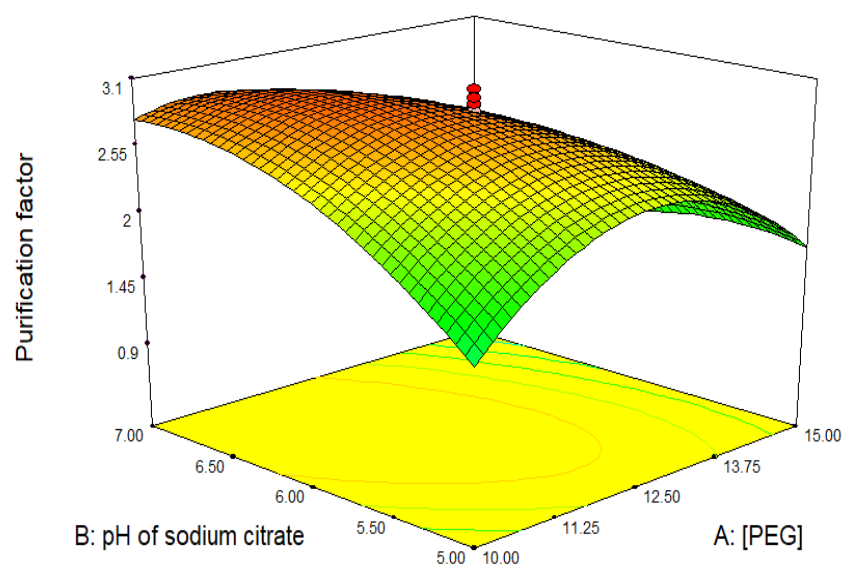

(B)

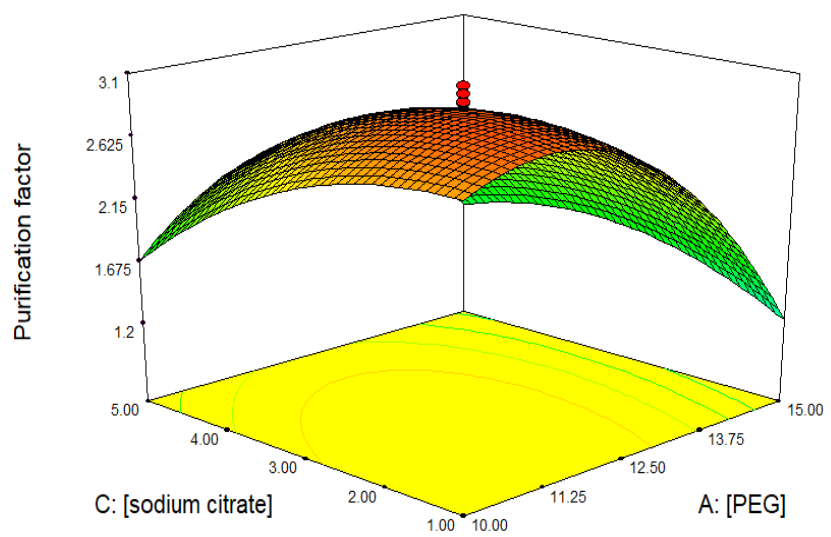

(C)

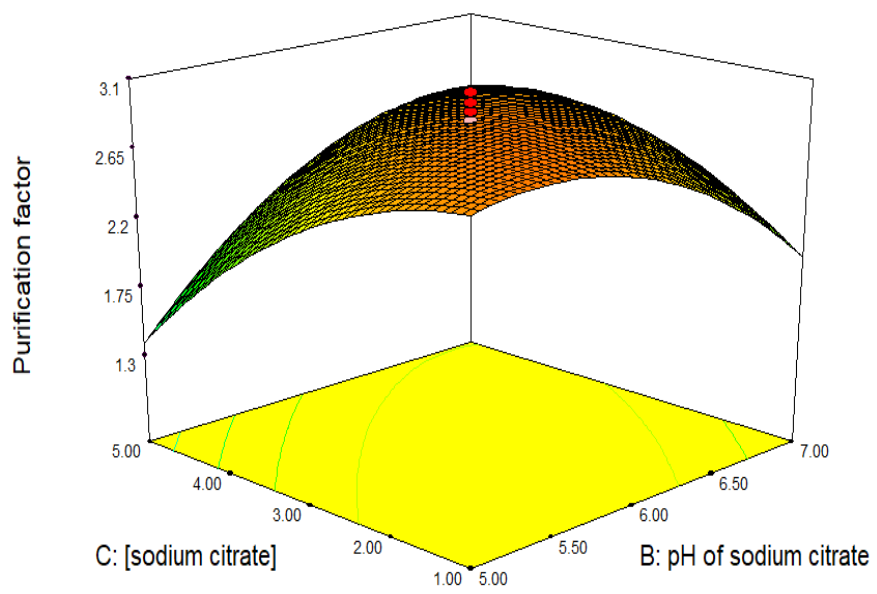

Figure 3. 3D surface plot for purification factor obtained for the combination effect of (A) concentration of PEG 4000 and $\mathrm{pH}$ of sodium citrate, (B) concentration of PEG 4000 and sodium citrate concentration and $(\mathbf{C}) \mathrm{pH}$ and concentration of sodium citrate.

\subsection{Purity of BLIS on SDS-PAGE}

The purified BLIS was analyzed using 12\% SDS-PAGE image gel to determine the purity. Figure 4 shows that the BLIS was partially purified by AIRS. There is a band with an approximate molecular size of $14 \mathrm{kDa}$ in Lane 2 which was assumed to be the BLIS that had been partially purified from L. bulgaricus FTDC 1211 by AIRS. 


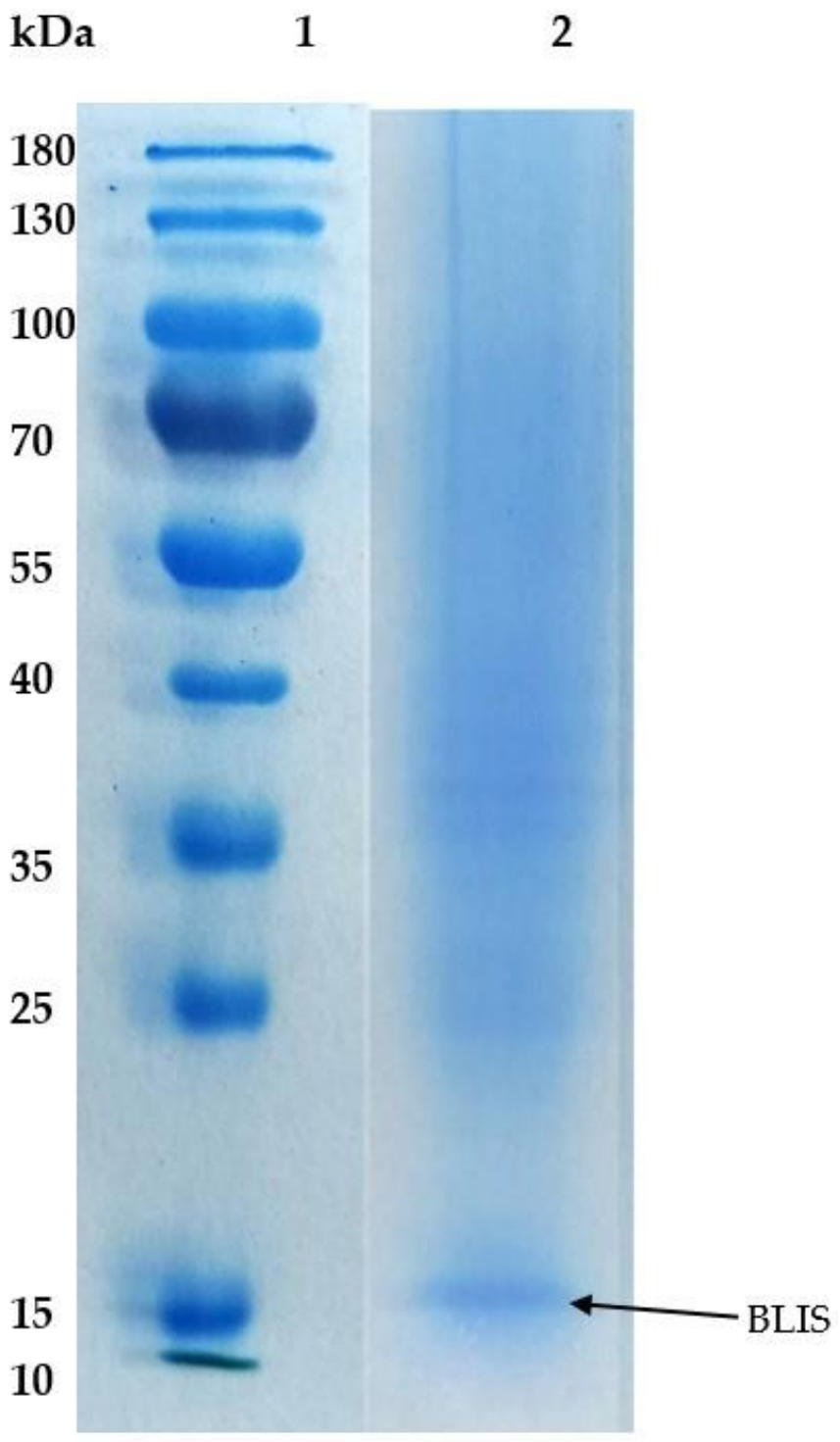

Figure 4. SDS-PAGE profile. Lane 1: standard marker with molecular weight of 10 to $180 \mathrm{kDa}$. Lane 2: partially purified BLIS from L. bulgaricus FTDC1211.

\section{Discussion}

In order to confirm the antimicrobial effect of the CCFS on S. aureus ATCC12600, a well diffusion assay was used to determine the inhibitory activity of L. bulgaricus FTDC 1211. The results showed that L. bulgaricus FTDC 1211 can inhibit the growth of S. aureus. There is a consensus regarding the hypothesis that most bacteriocins interact with cell membrane anionic lipids of the target bacteria, causing their permeabilization through the formation of pores. Eventually, this interaction can cause the death of the target cell, promoting the dissipation of the proton motive force (PMF) and the inhibition of amino acids transport. PMF is involved in several processes in the cell membrane, such as the accumulation of ions and metabolites, and ATP synthesis [10].

BLIS produced by L. bulgaricus FTDC 1211 was purified via a single-step AIRS. The results from the effect of molecular weight and concentration of PEG on the purification of BLIS by AIRS revealed that the PEG molecular weight had an effect on the purification of BLIS in AIRS. As the PEG mass increased from 2000 to 4000, the surface hydrophobicity increased in the PEG impregnated Amberlite XAD-4 resins due to the reduction of the hydroxyl groups for the higher chain length PEG, as compared to the lower chain length $[9,11]$. Hence, BLIS with a hydrophobic surface area were selectively adsorbed into the PEG impregnated resins, subsequently increasing the purification factor and recovery yield. 
On the other hand, increase in PEG mass led to an increase of excluded volume, in which there was less space to accommodate protein in PEG impregnated Amberlite XAD-4 resins. Hence, the purification factor decreased with increasing the PEG molecular weight to 6000 and 8000 due to the excluded volume effect. Sabrina da Silva Sabo et al. [12] reported that a low concentration of PEG could increase the purification factor of BLIS in an aqueous two phase system. Hence, 10\% (w/w) of PEG 4000 with the highest purification factor was used in further experiments.

The results from the effect of the sodium citrate concentration on the purification factor and yield of BLIS in AIRS demonstrated that there was a decreasing trend in the purification factor as the sodium citrate concentration increased. This could be attributed to the higher concentration of salt, which led to a salting-out effect of the protein molecule [13]. The salting-out effect caused the precipitation of the BLIS in the bulk salt phase and prevented it from binding to PEG impregnated resins. Unlike ATPS, a high concentration of salt is usually needed for the phase formation in AIRS, as it could increase the interfacial tension and density difference between the PEG and salt phases [8,14]. Hence, 2.5\% $(w / w)$ sodium citrate was selected for use in subsequent experiments.

The effect of $\mathrm{pH}$ of sodium citrate on the purification factor and recovery yield was due to the manipulation of the protein charges in the system. As the $\mathrm{pH}$ increased from 6 to 9 , the purification factor gradually decreased. This could be due to the effect of $\mathrm{pH}$ on the charge of the biomolecules, their ion composition and the surface character of contaminating materials, which resulted in a variation in the biomolecule extraction by the resins. The $\mathrm{pH}$ of the salt could affect the extraction of the targeted protein, in which the adsorption of biomolecule markedly increased when the protein charge changed from positive to neutral [15]. There was no net molecular charge for proteins in a solution with the same $\mathrm{pH}$ of their pI. Electrostatic repulsion between protein molecules would then be at a minimum and interactions via hydrophobic groups on the surface of the protein would occur [16]. Therefore, the $\mathrm{pH}$ of the system may be manipulated in order to promote selective separation.

Increasing the $\mathrm{NaCl}$ concentration from 0 to $4 \%(w / w)$ gradually increased the purification factor. However, further increase in $\mathrm{NaCl}$ concentration resulted in a decrease in the purification factor. The addition of $\mathrm{NaCl}$ increased the difference in the hydrophobicity of PEG and sodium citrate, causing more BLIS to be extracted to the PEG impregnated resins [8]. In this study, the extraction and back-extraction of the target biomolecule was driven by the presence of a neutral salt, i.e., $\mathrm{NaCl}$. $\mathrm{NaCl}$ is commonly used in PEG-salt ATPS to alter the partitioning behavior of proteins by distributing differential to the salt ions between the polymer and salt [11].

BLIS was partially purified by AIRS with approximate molecular size of $14 \mathrm{kDa}$. Based on previous findings by Nour I. et al. [17] and Kim et al. [18], the molecular weights of BLISs produced from L. bulgaricus were $14.4 \mathrm{kDa}$ and $45 \mathrm{kDa}$. In a study by Balogu et al. [19], the CCFS of L. bulgaricus Y34, purified using ammonium sulphate precipitation, TCA precipitation, followed by ultrafiltration, had $8.8 \%$ bacteriocin recovery with a $\mathrm{P}_{\mathrm{FT}}$ of 11.8 at the end of the purification process. The ammonium sulfate and TCA precipitation processes in their study yielded $17.5 \%$ bacteriocin recovery and a $\mathrm{P}_{\mathrm{FT}}$ of 5.7. Higher $\mathrm{P}_{\mathrm{FT}}$ could be observed after the precipitation steps. Hence, the precipitation steps could be used in our study to strengthen the purification performance

\section{Materials and Methods}

\subsection{Supplies}

Polyethylene glycols (PEGs) with an average molecular weight of $2000 \mathrm{~g} / \mathrm{mol}, 4000 \mathrm{~g} / \mathrm{mol}$ and $6000 \mathrm{~g} / \mathrm{mol}$, nutrient agar and nutrient broth were purchased from Merck (Darmstadt, Germany) while PEG $8000 \mathrm{~g} / \mathrm{mol}$ was obtained from OmniPur Plus (Darmstadt, Germany). Potassium citrate was sourced from HmbG (Hamburg, Germany). De Man Ragosa and Sharpe (MRS) broth, Amberlite XAD4 with pore size distribution of $\sim 0.98 \mathrm{~mL} / \mathrm{g}$ pore volume, sodium chloride, acetone, acrylamide/bis-acrylamide (30\% solution), ammonium persulphate were supplied from Sigma Aldrich (St. Louis, MO, USA). 0.5M Tris-HCl buffer (pH 6.8), $1.5 \mathrm{M}$ Tris- $\mathrm{HCl}$ buffer ( $\mathrm{pH} 8.8$ ), sodium dodecyl 
sulphate, tetramethylenediamine (TEMED) and concentrated Bradford reagent were purchased from Bio-Rad (Hercules, CA, USA). PageBlue Protein Staining solution was obtained from Thermo Scientific (Waltham, MA, USA).

\subsection{Bacteriocin-Producing LAB and BLIS Preparation}

A BLIS producing strain, L. bulgaricus FTDC 1211 isolated from cow milk was obtained from Bioprocess Technology laboratory, School of Industrial Technology, Universiti Sains Malaysia. The primary culture was prepared by inoculating $1 \mathrm{~mL}$ of bacterial stock culture with $9 \mathrm{~mL}$ of MRS broth and incubated at $37^{\circ} \mathrm{C}$ for $24 \mathrm{~h}$. The cultivation of L. bulgaricus FTDC 1211 was carried out with inoculation of $1 \mathrm{~mL}$ of inoculum into $9 \mathrm{~mL}$ of sterile MRS broth containing $2 \%(w / v)$ of sucrose and incubated at $37^{\circ} \mathrm{C}$ for $72 \mathrm{~h}$ under anaerobic condition. After $72 \mathrm{~h}$, the culture was centrifuged (Centrifuge Model 5500, Kubota, Japan) at 10,000 rpm, for $20 \mathrm{~min}$ at $4{ }^{\circ} \mathrm{C}$ and the cell culture free supernatant (CCFS) was kept at $-20{ }^{\circ} \mathrm{C}$ prior to use.

\subsection{Purification of BLIS}

In our preliminary study, VitraPor porous glass beads with diameter of $4.0 \mathrm{~mm}$ and $8.0 \mathrm{~mm}$ were used. The result showed that Amberlite XAD4 resins had higher adsorption performance towards BLIS in AIRS (Data not shown). Hence, XAD4 was chosen for the present study. The impregnation of the PEG into Amberlite XAD4 resins was carried out using the dry impregnation method, as described by Abdul Aziz [9]. A total of $1 \mathrm{~g}(w / w)$ of PEG was needed to fully impregnate $1 \mathrm{~g}$ of Amberlite XAD4 resins. The crude BLIS was mixed with sodium citrate and $4 \% \mathrm{NaCl}$ at a ratio of $1: 1$. The mixture $(2.5 \mathrm{~mL})$ was loaded to the impregnated Amberlite XAD4 resins and equilibrated for $30 \mathrm{~min}$. Back extraction was performed using $2.5 \mathrm{~mL}$ of sodium citrate in the absence of $\mathrm{NaCl}$. All experiments were performed in triplicate, and the back-extracted fraction was assessed for antimicrobial activity.

Furthermore, the effect of molecular weight $(2000$ to $8000 \mathrm{~g} / \mathrm{mol})$ and concentration $(10$ to $40 \%, w / w)$ of PEGs, concentration of sodium citrate solution (2.5 to $10 \%, w / w)$, $\mathrm{pH}$ of sodium citrate solution (5 to 9 ) and concentration of $\mathrm{NaCl}(1$ to $5 \%, w / w)$ on the purification of BLIS were studied by using one-factor-at-a-time method. The significant parameters were further optimized using response surface methodology. A five-level, full-factorial central composite design (CCD) was designed using Design-Expert (version 7.1.6, Stat-Ease Inc., Minneapolis, MN, USA) for regression modelling and data interpretation. The observed responses from CCD design were then fitted to the polynomial Equation (2)

$$
Y=\beta_{0}+\sum_{i=1}^{k} \beta_{i} x_{i}+\sum_{i=1}^{k} \beta_{i i} x_{i}^{2}+\sum_{i=1}^{k} \sum_{j=1}^{k} \beta_{i j} x_{i} \beta_{i i} x_{j}+\varepsilon
$$

where $Y$ is the predicted response; $i$ and $j$ are the index numbers for the pattern; $\beta$ is the offset term; $\beta_{i}, \beta_{i i}$, and $\beta_{i j}$ are the coefficients for the linear, quadratic, and interaction effects, respectively; $x_{i}$ and $x_{j}$ are the coded variables; and $\varepsilon$ is the error.

The regression equation was optimized by an iterative method to achieve the optimum values. From this step, the optimum parameters with highest desirability in purification factor were determined.

\subsection{Antimicrobial Activity Assay}

The antimicrobial activity of BLIS from L. bulgaricus FTDC 1211 was evaluated using well-diffusion assay as described by Ng et al. [20]. S. aureus ATCC 12600 was cultured overnight in nutrient broth and agitated at $150 \mathrm{rpm}$, at $30^{\circ} \mathrm{C}$. The culture was adjusted to $1-2 \times 10^{6} \mathrm{CFU} / \mathrm{mL}$. A prepared nutrient agar was inoculated with $S$. aureus using a cotton swab, and a well was made on the agar plate. Then, $100 \mu \mathrm{L}$ of sample was pipetted into the well. Streptomycin with dose of $15 \mu \mathrm{g}$ was used as positive control. 
The nutrient agar plate was incubated at $37^{\circ} \mathrm{C}$ for $24 \mathrm{~h}$. The diameter of the clear zone was recorded and the BLIS activity was calculated using Equation (3):

$$
\text { BLIS activity }\left(\mathrm{mm}^{2} / \mathrm{mL}\right)=\frac{(L 2-L 1)}{V}
$$

where $L 2$ and $L 1$ are the diameters of clear zone and well zone, respectively, and $V$ is the volume of CCFS.

\subsection{Total Protein Content Determination}

The total protein content was determined using Bradford method [21]. Briefly, $10 \mu \mathrm{L}$ of sample was mixed with $200 \mu \mathrm{L}$ of diluted concentrated Bradford dye reagent $(1 \mathrm{~mL}$ of dye reagent diluted with $4 \mathrm{~mL}$ of distilled water) in a 96-well microplate. The samples were incubated at room temperature for $10 \mathrm{~min}$ before reading the absorbance at $595 \mathrm{~nm}$ using a microplate reader (Halo MPR-96 Visible Microplate Reader, Dynamica). Bovine Serum Albumin (BSA) at a concentration range of 0.0625 to $1.0 \mathrm{mg} / \mathrm{mL}$ was used as standard curve and the total protein content was calculated using BSA standard curve. All the experiments were performed in triplicate.

\subsection{Sodium Dodecyl Sulfate Polyacrylamide Gel Electrophoresis}

Prior to SDS-PAGE, BLIS was precipitated using trichloroacetic acid (TCA). First, $200 \mu \mathrm{L}$ of TCA stock solution was added to the $800 \mu \mathrm{L}$ sample and incubated in $4{ }^{\circ} \mathrm{C}$ for $15 \mathrm{~min}$ before centrifugation at 13,000 rpm for $10 \mathrm{~min}$. The pellet was then washed with $200 \mu \mathrm{L}$ of cold acetone. The washing steps were repeated three times and the pellet were dried in a drying cabinet at $60{ }^{\circ} \mathrm{C}$ for $30 \mathrm{~min}$. SDS-PAGE of the purified BLIS was performed using $12 \%$ resolving gel and $4 \%$ stacking gel. Then, $100 \mu \mathrm{L}$ of Laemmli sample buffer was added to the pellet, which was heated at $95^{\circ} \mathrm{C}$ for $15 \mathrm{~min}$. Next, $15 \mu \mathrm{L}$ of samples and $5 \mu \mathrm{L}$ of marker (size range from 10 to $180 \mathrm{kDa}$ ) were loaded into the well and the electrophoresis was performed at a constant voltage of $120 \mathrm{~V}$ for $60 \mathrm{~min}$. The gel was stained overnight using PageBlue protein staining solution and destained using a solution containing $10 \%$ of methanol and $10 \%$ of acetic acid overnight. The image of the band was subsequently captured using gel imaging system (UV Tech Gel Imaging System, Vivantis, Malaysia).

\subsection{Determination of Purification Factor and Recovery Yield}

The specific activity $(\mathrm{SA})$, purification factor $\left(\mathrm{P}_{\mathrm{FT}}\right)$ and recovery yield of BLIS were calculated using the following equations.

The SA defined as the ratio between the depleted BLIS antimicrobial activity $\left(\mathrm{mm}^{2} / \mathrm{mL}\right)$ and the concentration of the total protein content were calculated using Equation (4):

$$
\mathrm{SA}\left(\mathrm{mm}^{2} / \mathrm{mg}\right)=\frac{\text { BLIS antimicrobial activity }\left(\frac{\mathrm{mm}^{2}}{\mathrm{~mL}}\right)}{[\text { total protein }]\left(\frac{\mathrm{mg}}{\mathrm{mL}}\right)}
$$

$\mathrm{P}_{\mathrm{FT}}$ is defined as the ratio of the SA in the depleted BLIS to SA in crude BLIS was calculated based on Equations (5) and (6), respectively.

$$
\text { Purification factor, } \mathrm{P}_{\mathrm{FT}}=\frac{\mathrm{SA} \text { in back extraction solution }\left(\frac{\mathrm{mm}^{2}}{\mathrm{mg}}\right)}{\mathrm{SA} \text { in crude BLIS }\left(\frac{\mathrm{mm}^{2}}{\mathrm{mg}}\right)}
$$


The recovery yield of the BLIS was estimated using Equation (5):

$$
\text { Recovery yield }(\%)=\frac{\begin{array}{c}
\text { BLIS antimicrobial activity in } \\
\text { back extraction solution }
\end{array}}{\begin{array}{c}
\text { BLIS antimicrobial } \\
\text { activity in crude BILS }
\end{array}} \times 100
$$

\section{Conclusions}

BLIS from L. bulgaricus FTDC 1211 was partially purified in this study. The partially purified BLIS with an estimated size of $14 \mathrm{kDa}$ and total recovery of $82.96 \%$ with a purification factor of 3.26 was achieved under the optimum condition of 11.4\% (w/w) PEG 4000 impregnated on Amberlite XAD4 and $2 \%(w / w)$ sodium citrate at $\mathrm{pH} 6.06$ with $4 \%(w / w) \mathrm{NaCl}$. These results demonstrate that AIRS could be used as an alternate purification system in the primary recovery step. The BLIS purification method from fermentation broth described in this study need to be further improved. Regarding the use of the AIRS, additional purification methods such as ultrafiltration, anion exchange chromatography, gel-filtration for reduction of the contaminants, and HPLC or FPLC chromatography could be utilized. The purified BLIS can be sent for N-terminal sequencing. Degenerative primers based on the amino acid sequences can then be synthesized. The gene cluster could be amplified by PCR and the ORFs in the gene cluster could be analyzed and compared with the known bacteriocin. Even though AIRS are capable of purifying BLIS, there are however during the impregnation of polymer into Amberlite XAD4, leaching of the polymer occurs. Study on the mechanism of leached PEG will deepen our understanding of the system. Furthermore, study of the adsorption kinetics during the extraction of BLIS is required to understand the system. In addition, the repetition of the flow-through and recyclability of the system could be further investigated to improve the applicability of the system.

Author Contributions: Conceptualization, S.A., J.S.T. and A.B.A.; Data curation, S.A. and J.S.T.; Formal analysis, N.F.H.A.A., S.A., Z.J.N., M.A.Z. and J.S.T.; Funding acquisition, J.S.T.; Investigation, N.F.H.A.A., S.A. and J.S.T.; Methodology, N.F.H.A.A., S.A., Z.J.N., M.A.Z. and J.S.T.; Project administration, S.A., J.S.T. and A.B.A.; Resources, J.S.T. and A.B.A.; Supervision, S.A. and J.S.T.; Validation, S.N.O. and A.B.A.; Visualization, A.B.A.; Writing-original draft, N.F.H.A.A., Z.J.N. and M.A.Z.; Writing-review \& editing, S.A., J.S.T. and A.B.A. All authors have read and agreed to the published version of the manuscript.

Funding: This work was funded by Prototype Development Research Grant Scheme under Ministry of Higher Education, Malaysia (203/PTENKIND/6740048).

Conflicts of Interest: The authors have declared no conflict of interest.

\section{References}

1. Morell, E.A.; Balkin, D.M. Methicillin-resistant Staphylococcus aureus: A pervasive pathogen highlights the need for new antimicrobial development. Yale J. Biol. Med. 2010, 83, 223-233.

2. Abbasiliasi, S.; Tan, J.S.; Ibrahim, T.A.T.; Ramanan, R.N.; Vakhshiteh, F.; Mustafa, S.; Ling, T.C.; Rahim, R.A.; Ariff, A.B. Isolation of Pediococcus acidilactici Kp10 with ability to secrete bacteriocin-like inhibitory substance from milk products for applications in food industry. BMC Microbiol. 2012, 12, 260. [CrossRef] [PubMed]

3. Hor, Y.Y.; Liong, M.T. Use of extracellular extracts of lactic acid bacteria and bifidobacteria for the inhibition of dermatological pathogen Staphylococcus aureus. Dermatol. Sin. 2014, 32, 141-147. [CrossRef]

4. Abbasiliasi, S.; Tan, J.S.; Ibrahim, T.A.T.; Kadkhodaei, S.; Ng, H.S.; Vakhshiteh, F.; Ajdari, Z.; Mustafa, S.; Ling, T.C.; Rahim, R.A. Primary recovery of a bacteriocin-like inhibitory substance derived from Pediococcus acidilactici Kp10 by an aqueous two-phase system. Food Chem. 2014, 151, 93-100. [CrossRef] [PubMed]

5. Zhang, J.; Yang, Y.; Yang, H.; Bu, Y.; Yi, H.; Zhang, L.; Han, X.; Ai, L. Purification and partial characterization of Bacteriocin Lac-B23, a novel Bacteriocin production by Lactobacillus plantarum J23, isolated from Chinese traditional fermented milk. Front. Microbiol. 2018, 9, 2165. [CrossRef]

6. Yamato, M.; Ozaki, K.; Ota, F. Partial purification and characterization of the bacteriocin produced by Lactobacillus acidophilus YIT 0154. Microbiol. Res. 2003, 158, 169-172. [CrossRef] 
7. Abriouel, H.; Valdivia, E.; Martınez-Bueno, M.; Maqueda, M.; Gálvez, A. A simple method for semi-preparative-scale production and recovery of enterocin AS-48 derived from Enterococcus faecalis subsp. liquefaciens A-48-32. J. Microbiol. Methods 2003, 55, 599-605. [CrossRef]

8. Tan, J.S.; Abbasiliasi, S.; Ariff, A.B.; Ng, H.S.; Bakar, M.H.A.; Chow, Y.H. Extractive purification of recombinant thermostable lipase from fermentation broth of Escherichia coli using an aqueous polyethylene glycol impregnated resin system. 3 Biotech 2018, 8, 288. [CrossRef]

9. Abdul Aziz, N.F.H.; Abbasiliasi, S.; Ariff, A.B.; Ng, H.S.; Lan, J.C.-W.; Ahmad, R.; Tan, J.S. Optimization of recovery of esterase from Serratia marcescens using combination of the solvent impregnated resin and aqueous two-phase extraction techniques. Sep. Sci. Technol. 2018, 53, 2952-2960. [CrossRef]

10. Da Costa, R.J.; Voloski, F.L.; Mondadori, R.G.; Duval, E.H.; Fiorentini, Â.M. Preservation of meat products with bacteriocins produced by lactic acid bacteria isolated from meat. J. Food Qual. 2019, 2019, 4726510. [CrossRef]

11. Ketnawa, S.; Rungraeng, N.; Rawdkuen, S. Phase partitioning for enzyme separation: An overview and recent applications. Int. Food Res. J. 2017, 24, 1-24.

12. Da Silva Sabo, S.; Lopes, A.M.; de Carvalho Santos-Ebinuma, V.; de Oliveira Rangel-Yagui, C.; de Souza Oliveira, R.P. Bacteriocin partitioning from a clarified fermentation broth of Lactobacillus plantarum ST16Pa in aqueous two-phase systems with sodium sulfate and choline-based salts as additives. Process Biochem. 2018, 66, 212-221. [CrossRef]

13. Nainegali, B.; Iyyaswami, R.; Belur, P. Aqueous two-phase extraction of anthocyanin from fruits of garcinia indica. Int. J. Earth Sci. Eng. 2017, 10, 688-692.

14. Asenjo, J.A.; Andrews, B.A. Aqueous two-phase systems for protein separation: A perspective. J. Chromatogr. A 2011, 1218, 8826-8835. [CrossRef]

15. Marcos, J.; Fonseca, L.; Ramalho, M.; Cabral, J. Variation of penicillin acylase partition coefficient with phase volume ratio in poly (ethylene glycol)-sodium citrate aqueous two-phase systems. J. Chromatogr. B 1998, 711, 295-299. [CrossRef]

16. Chaiwut, P.; Pintathong, P.; Rawdkuen, S. Extraction and three-phase partitioning behavior of proteases from papaya peels. Process Biochem. 2010, 45, 1172-1175. [CrossRef]

17. Nour, I.; Fattouh, F.; El-Adawi, H. Antibacterial bioactivity of selected lactic acid bacterial strains against some human pathogenic bacteria. Int. J. Pharmacol. 2015, 11, 440-447.

18. Kim, H.J.; Kim, J.H.; Son, J.H.; Seo, H.J.; Park, S.J.; Paek, N.S.; Kim, S.K. Characterization of bacteriocin produced by Lactobacillus bulgaricus. J. Microbiol. Biotechnol. 2004, 14, 503-508.

19. Balogu, T.; Yunusa, A.; Aliyu, H. Antimicrobial efficiency of purified and characterized bacteriocins produced by Lactobacillus bulgaricusY34 and LactococcuslactisN22 isolated from fermented milk products. Int. J. Adv. Res. 2013, 1, 63-70.

20. Ng, Z.J.; Zarin, M.A.; Lee, C.K.; Phapugrangkul, P.; Tan, J.S. Isolation and characterization of Enterococcus faecium DSM 20477 with ability to secrete antimicrobial substance for the inhibition of oral pathogen Streptococcus mutans UKMCC 1019. Arch. Oral Biol. 2020, 110, 104617. [CrossRef]

21. Bradford, M.M. A rapid and sensitive method for the quantitation of microgram quantities of protein utilizing the principle of protein-dye binding. Anal. Biochem. 1976, 72, 248-254. [CrossRef]

Sample Availability: Samples of the compounds are available from the authors.

Publisher's Note: MDPI stays neutral with regard to jurisdictional claims in published maps and institutional affiliations.

(C) 2020 by the authors. Licensee MDPI, Basel, Switzerland. This article is an open access article distributed under the terms and conditions of the Creative Commons Attribution (CC BY) license (http://creativecommons.org/licenses/by/4.0/). 